\title{
Exposure to Emissions from Kerosene Cooking Stoves and the Pulmonary Health Status of Women in Olorunda Community, Ibadan, Nigeria
}

\author{
B. A. Adeniji1 ${ }^{*}$, G. R. E. E. Ana1, B. O. Adedokun², O. I. Ige ${ }^{3}$ \\ ${ }^{1}$ Department of Environmental Health Sciences, Faculty of Public Health, University of Ibadan, Ibadan, Nigeria \\ ${ }^{2}$ Department of Epidemiology and Medical Statistics, Faculty of Public Health, University of Ibadan, \\ Ibadan, Nigeria \\ ${ }^{3}$ Department of Medicine, Faculty of Clinical Sciences, University of Ibadan, Ibadan, Nigeria \\ Email: bamideleadeniji@yahoo.com
}

Received 31 March 2015; accepted 29 April 2015; published 4 May 2015

Copyright (C) 2015 by authors and Scientific Research Publishing Inc.

This work is licensed under the Creative Commons Attribution International License (CC BY). http://creativecommons.org/licenses/by/4.0/

(c) (i) Open Access

\section{Abstract}

Exposure to high $\mathrm{PM}_{10}$ by women and children for hours on a daily basis in poor ventilated kitchen may lead to respiratory morbidity among this vulnerable group. In Nigeria, data on the levels of air pollutants associated with kerosene stove combustion are very scarce. Like-wise little had been documented on the pulmonary health of women exposed to kerosene stove emission. This study was carried out to measure the levels of kerosene combustion emissions within kitchen environments and also assess the pulmonary function status of the exposed women at baseline. Particulate matter $\left(\mathrm{PM}_{10}\right)$ and gaseous emissions (GE) were measured in six purposively selected clusters of regular kerosene stove users (KSU) using gravimetric sampler and gas monitors, respectively and their values compared with WHO guideline limits. 167 randomly selected KSU were surveyed to elicit their socio demographic features. A spirometer was used to assess the lung function status $\left(F^{2} V_{1}\right)$ of $72 \mathrm{KSU}$ in six neighbourhood kitchen clusters. Data were analysed using descriptive statistics, and Pearson's correlation tests. Respondents' mean age was $38+12.9$ years. Mean duration of exposure to GE was 18.9 + 9.8 years. Mean $P M_{10}$ was $248.1+14.1 \mu \mathrm{g} / \mathrm{m}^{3}$ and ten folds higher than WHO guideline limit of $25 \mu \mathrm{g} / \mathrm{m}^{3}$. Mean GE in ppm were: $\mathrm{CO}(0.00), \mathrm{CO}_{2}(200.1+$ 12.4), $\mathrm{SO}_{2}(0.01+0.00)$ and $\mathrm{NO}_{2}(0.00)$. Mean $\mathrm{FEV}_{1}$ among $\mathrm{KSU}$ was $2.0+0.5$ litres which was significantly lower than the mean predicted value of $2.7 \pm 0.5$ litres. There was a negative correlation between $\mathrm{PM}_{10}$ and $\mathrm{FEV}_{1}(\mathrm{r}=\mathbf{- 0 . 7 5 3 9}, \mathrm{p}>0.05)$. Safer cooking methods and practices to obviate health hazards are advocated.

"Corresponding author.

How to cite this paper: Adeniji, B.A., Ana, G.R.E.E., Adedokun, B.O. and Ige, O.I. (2015) Exposure to Emissions from Kerosene Cooking Stoves and the Pulmonary Health Status of Women in Olorunda Community, Ibadan, Nigeria. Journal of Environmental Protection, 6, 435-445. http://dx.doi.org/10.4236/jep.2015.65042 
Keywords

Kerosene Stoves, Air Pollution, Lung Function Status, Rural Women, Ibadan

\section{Introduction}

About half of the world's population is exposed to smoke from burning biomass fuel at home [1]. It has been estimated that the use of fuels to cook and heat is common in developing countries, with an estimated 3 billion people exposed to smoke from these fuels [2]. It has also been estimated by Prüss-Ustün et al. that biomass smoke exposure is responsible for about 1.5 million early deaths per year [3].

Exposure to emissions from firewood cooking stove has been implicated as a causal agent of several diseases in developing countries, including acute respiratory infections (ARI), otitis media (middle ear infection), chronic obstructive pulmonary diseases (COPD), lung cancer, asthma, cancer of the nasopharynx and larynx pulmonary tuberculosis, prenatal conditions and low birth weight, and disease of the eye such as cataract and blindness [4]. Much evidence has been documented, for example, that links biomass fuel combustion with the incidence of chronic bronchitis in women and of ARI in children [5].

It has been estimated by Balakrishnan et al. [6] that combustion of biomass fuel generates higher emissions than fossil fuels like kerosene and liquefied petroleum gas. However, the concentration of $\mathrm{PM}_{10}$ generated by kerosene cooking stoves is still very high when compared with WHO standard [6]. Exposure to this high $\mathrm{PM}_{10}$ by women and children for hours on a daily basis in poor ventilated kitchen may lead to respiratory morbidity among this vulnerable group.

In Nigeria, data on the levels of air pollutants associated with kerosene stove combustion are very scarce. Likewise little had been documented on the pulmonary health of women exposed to kerosene stove emission. The objective of this study, therefore, was to measure the levels of kerosene combustion emissions within kitchen environments as well as to assess at baseline the pulmonary function status of the exposed women.

\section{Materials and Methods}

\subsection{Study Area}

This study was carried out at Olorunda-Abaa community, Lagelu Local Government Area (LGA) of Ibadan in Oyo State (Figure 1). Ibadan is the capital of Oyo State in Nigeria and the largest indigenous city in West Africa. It lies between latitude latitude $7^{\circ}$ and $9^{\circ} 30^{\prime}$ east of prime meridian [7]. Ibadan covers a land area of 12 kilometres radius with Mapo hall as the centre. It has an altitude generally ranging from 152 to $213 \mathrm{~m}$ with isolated ridges and peaks rising to $274 \mathrm{~m}$ [8]. Ibadan comprises eleven (11) LGAs. Five of these LGAs are in Ibadan metropolis while the remaining six including Lagelu are at the outskirts of the capital city. Lagelu shares boundary with Iwo Local Government in the North and Egbeda Local Government in the West. It is also bounded in the South by Ibadan North East Local Government and Akinyele Local Government by the East. The area is characterized by Savannah climate and has a good breed of vegetation.

\subsection{The Study Population}

The study population comprised women resident in Olorunda community for upwards of two years. They were mostly rural women, that is, house wives, petty traders, farmers and those involved in other forms of vocations. These women use kerosene stoves exclusively for cooking. They were found sometimes with children in the cooking environments.

\subsection{Selection of Houses and Subjects}

A three-stage random sampling technique was employed to select houses for the study. Lagelu was picked from the six peripheral LGAs while Olorunda was selected from the list of the rural communities. Finally, only houses where women utilize kerosene stove for cooking were purposively selected from the study community following an initial enumeration exercise. From these houses 167 women were randomly recruited for the study of which 72 consented for the lung function test (spirometry). 


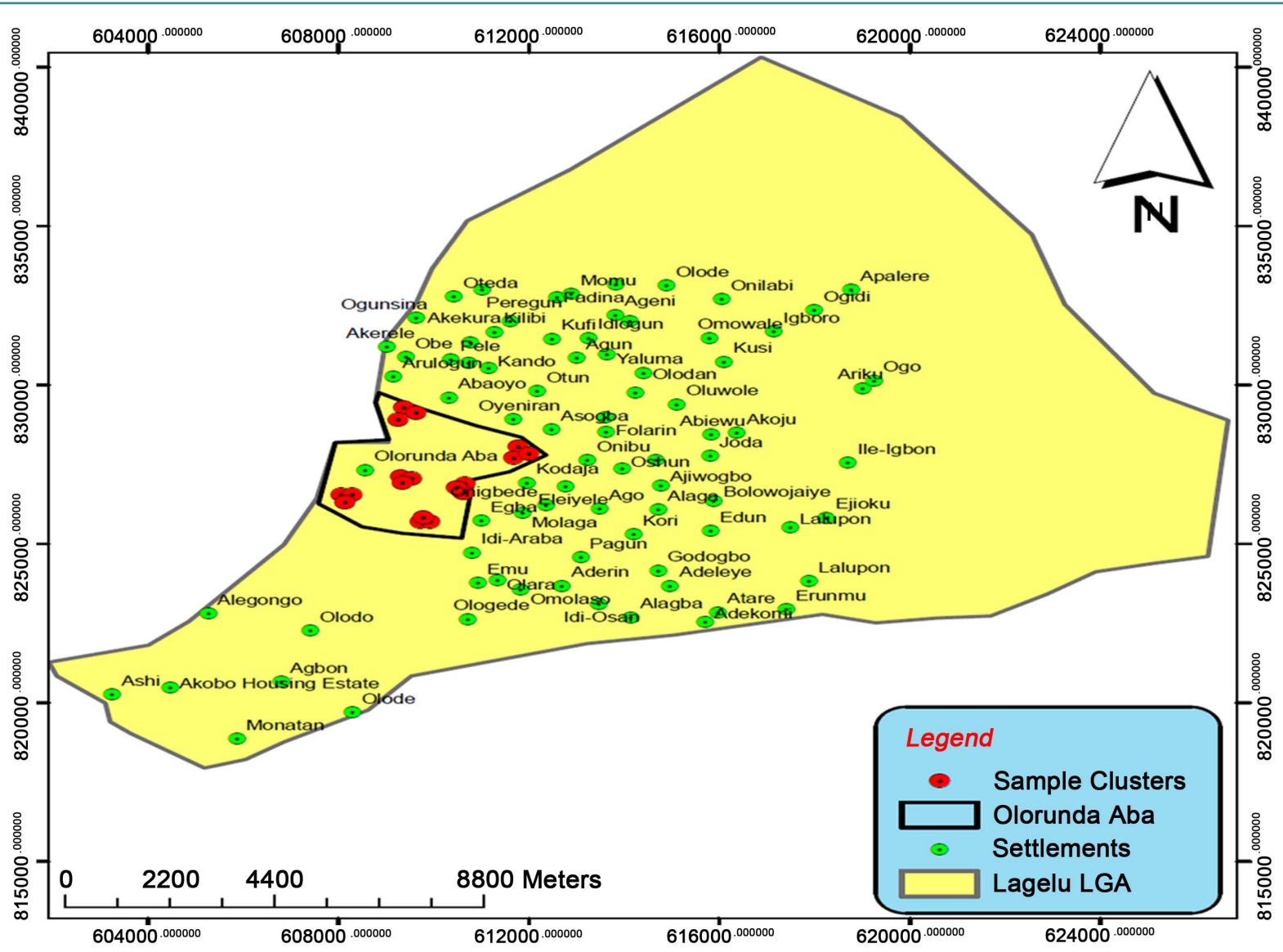

Figure 1. Map of Lagelu showing the study area.

\subsection{Air Sampling}

\subsubsection{Calibration and Standardisation of PM Sampler}

A gravimetric particulate air sampler made by Science Source, Walboro, USA was used to sample particles of aerodynamic size $10 \mu \mathrm{m}\left(\mathrm{PM}_{10}\right)$. The sampler is cylindrical in shape and about $50 \mathrm{~cm}$ high and $18 \mathrm{~cm}$ in diameter with a roof covering that protects the inlet and impactor head on which filter is placed. An inbuilt pump draws the air carrying particles of various dimensions with only particle size $10 \mu \mathrm{m}$ allowed to pass through the inlet that finally settles on the filter paper. The flow rate was determined based on the pressure differentials from the manometer.

Prior to sampling, the equipment was calibrated to ensure that optimum average ambient conditions for temperature $\left(30^{\circ} \mathrm{C}\right)$, pressure $(1 \mathrm{~atm})$ and flow rate $(1.5 \mathrm{l} / \mathrm{min})$ were maintained. According to Vaughan et al. (1989) to ensure reproducibility of the results the substrate i.e. the filter paper used were examined, conditioned and equilibrated by oven drying at regulated temperature of about $40^{\circ} \mathrm{C}$ and allowed to cool after which it was placed in a desiccator and left with the lids slightly ajar in the weighing environment overnight prior to each sample weighing [9]. This period was observed to allow moisture in the substrates to come into equilibrium with the weighing room atmosphere to ensure optimum equilibration.

\subsection{2. $\mathrm{PM}_{10}$ Sampling in Kitchen Environments}

$\mathrm{PM}_{10}$ samples were collected from six purposively selected kitchen environments representing six different neighbourhood clusters where the subjects reside in the study community (Figure 1). The dimensions of the kitchen are K1 (3.10 m by $2.4 \mathrm{~m}), \mathrm{K} 2$ (3.00 m by $2.55 \mathrm{~m}), \mathrm{K} 3$ ( $2.95 \mathrm{~m}$ by $2.41 \mathrm{~m}), \mathrm{K} 4(3.30 \mathrm{~m}$ by $2.98 \mathrm{~m}), \mathrm{K} 5$ ( $3.20 \mathrm{~m}$ by $2.24 \mathrm{~m})$ and $\mathrm{K} 6(2.80 \mathrm{~m}$ by $2.38 \mathrm{~m})$. The kitchens were fairly ventilated with a good number having windows and some with and or without exhausts and fans. 
The sampler was placed one metre away from the stove whose $\mathrm{PM}_{10}$ was being measured and the filter paper whose initial weight was taken was placed on it. The sampler was then switched on and allowed to run for two hours. The initial and final flow rate was recorded by reading the pressure differential on the manometer. To obtain the final flow rate, the step was repeated just before the unit was switched off to obtain the average flow rate. The filter paper was carefully removed and placed in desiccators to eliminate any weight gain and then reweighed to determine the final weight.

The sampling procedure was carried out twice daily (morning: 7-9 am and evening: 5-7 pm) for each stove unit within a particular cluster for a period of one week during the wet season under stable prevailing wind conditions. The weight of the filter paper before and after the period of particulate sampling was determined gravimetrically, and the concentration of $\mathrm{PM}_{10}$ calculated based on the volume of air sampled expressed in $\mu \mathrm{g} / \mathrm{m}^{3}$. A detection limit of $10 \mu \mathrm{g} / \mathrm{m}^{3}$ was set with lower values regarded as not detectable. The concentration of $\mathrm{PM}_{10}$ obtained was compared with WHO guideline limits.

\subsubsection{Calibration and Standardisation of Gas Samplers}

Gaseous Emissions (GE) comprising carbon monoxide (CO), carbon dioxide $\left(\mathrm{CO}_{2}\right)$, sulphur dioxide $\left(\mathrm{SO}_{2}\right)$ and nitrogen dioxide $\left(\mathrm{NO}_{2}\right)$ were determined using digital gas monitors made by BW Canada. Prior to field measurements the instruments were calibrated accordingly using appropriate standard gases following the standard procedures as recommended by the instrument manual.

Gas sensor testing and calibration was done using a Digital volt meter (resolution to two decimal places), Crocodile clips, Flat-bedded screwdriver, Murco calibration kit which includes a cylinder of calibration gas, flow regulator, flexible non-absorbent tubing and a vented calibration hood. Detection specificity and sensitivity was achieved through the use of specially formulated chemical reagents, which react only with the sample gas or gases. As sample gas molecules were drawn through the Chemcassette ${ }^{\circledR}$ with a vacuum pump, they reacted with the dry chemical reagents and formed a coloured stain specific to that gas only. The intensity of this stain was proportionate to the concentration of the reactant gas, i.e. the higher the gas concentration, the darker was the stain.

\subsubsection{Gaseous Sampling in the Kitchen Environment}

The concentrations of Gaseous parameters viz $\mathrm{CO}, \mathrm{CO}_{2}, \mathrm{NO}_{2}, \mathrm{SO}_{2}$ were determined at the same designated kitchen locations as described above under the same prevailing conditions. In each location triplicate readings within 5 minutes interval were recorded and the average obtained. The detection limit of the gases $\mathrm{CO}, \mathrm{NO}_{2}$ and $\mathrm{SO}_{2}$ was set at zero while that of $\mathrm{CO}_{2}$ was set at $50 \mathrm{mg} / \mathrm{m}^{3}$. The concentrations of the gases were expressed in parts per million (ppm) and these was compared with WHO guideline limits.

\subsection{Questionnaire Administration}

A survey was carried out on human subjects using kerosene cooking stoves exclusively with the use of questionnaire. One hundred and sixty seven KSU who consented to participate in the study were administered with a validated pre-tested questionnaire. The questionnaire elicited information on the socio-demographic features and health conditions of the respondents. The questionnaire was pre-tested at a community with similar characteristics prior to administration to consented participants.

\subsection{Lung Function Test}

Seventy-two (43\%) of the study participants consented to participate in the lung function test. They were categorised into the six neighboured kitchen clusters comprising 12 exposed KSU. The eligibility criteria for study participants for the test were as follows:

1) The participants' ages must be between 15 years and 70 years.

2) Must not have family history of respiratory symptom or disease from the response got from questionnaire.

3) Must have been cooking with kerosene for a period not less than 5 years.

4) Must be a non-smoker.

5) Participants must be willing to take part in the study.

The lung function test was carried out using a Mini-Wright digital spirometer (Clement Clarke) to determine the actual forced expiratory volume in one second $\left(\mathrm{FEV}_{1}\right)$. The spirometer was calibrated to 0.00 before the par- 
ticipants were asked to inhale air and then exhale forcefully into the spirometer. This was repeated at three manoeuvres and the best attempt was recorded for each participant. The height and weight of the participants were measured using meter rule and weighing scale respectively to estimate the Body Mass Index (BMI). The sex, age and height of the participants were imputed into the lung function calculator to get the predicted $\mathrm{FEV}_{1}$. The actual $\mathrm{FEV}_{1}$ was compared with the predicted $\mathrm{FEV}_{1}$ from which the percentage predicted $\mathrm{FEV}_{1}$ was computed.

\subsection{Statistical Analysis}

Data were analysed using descriptive statistics and comparisons between $\mathrm{PM}_{10}$ and gaseous emissions with WHO guidelines were done. Pearson correlation analysis was used to test the relationship between $\mathrm{PM}_{10}$ and $\mathrm{FEV}_{1}$ as well as between BMI and $\mathrm{FEV}_{1}$. The Level of significance for all tests was put at $\mathrm{p}=0.05$.

\section{Results}

\subsection{Concentrations of Respirable Particulate Matter ( $\left.\mathrm{PM}_{10}\right)$}

The levels of $\mathrm{PM}_{10}$ measured at six kitchen locations measured twice daily are presented in Table 1 . The results showed that the concentrations of $\mathrm{PM}_{10}$ were higher in the evening hours than the morning hours. The highest average $\mathrm{PM}_{10}$ concentration (259.7 $\mu \mathrm{g} / \mathrm{m}^{3}$ and $271.3 \mu \mathrm{g} / \mathrm{m}^{3}$ ) for morning and evening measurements were recorded at location 3 . These values were both more than 10 fold higher than the WHO daily guideline limit of 25 $\mu \mathrm{g} / \mathrm{m}^{3}(\mathrm{p}<0.05)$.

\subsection{Concentration of Gaseous Emissions}

Concentrations of $\mathrm{CO}$ and $\mathrm{NO}_{2}$ were below detectable limits in the six locations. The concentration of $\mathrm{CO}_{2}$ was also highest in location 4 (Figure 2). The average $\mathrm{CO}_{2}$ levels for kerosene stove emissions at the six cluster

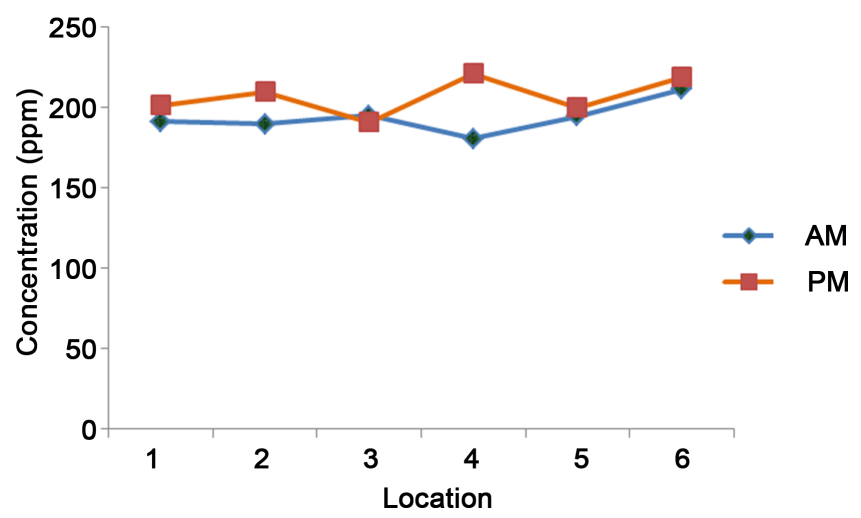

Figure 2. Concentration of $\mathrm{CO}_{2}$ in the morning (AM) and evening (PM) at the different kitchen locations.

Table 1. $\mathrm{PM}_{10}$ levels at selected kitchen locations.

\begin{tabular}{ccccc}
\hline & & $\mathbf{P M}_{\mathbf{1 0}}\left(\boldsymbol{\mu g} / \mathbf{m}^{\mathbf{3}}\right)$ & & WHO \\
\cline { 2 - 4 } Location & AM & $\mathbf{P M}$ & Daily Avg & \\
\hline K1 & 230.1 & 231.0 & $230.5 \pm 0.05$ \\
K2 & 260.3 & 267.5 & $263.9 \pm 2.72$ \\
K3 & 259.7 & 271.3 & $265.5 \pm 5.33$ & $\mathbf{2 5}$ \\
K5 & 228.1 & 245.6 & $236.9 \pm 8.47$ & $245.4 \pm 1.02$ \\
K6 & 244.7 & 245.6 & $246.6 \pm 13.5$ \\
\hline
\end{tabular}


locations combined were $193.5 \pm 9.92 \mathrm{ppm}$ (morning) and $206.7 \pm 11.7 \mathrm{ppm}$ (evening). The concentration of $\mathrm{SO}_{2}$ did not follow any particular trend (Figure 3). The average $\mathrm{SO}_{2}$ levels for kerosene stove emissions at the six cluster locations combined were $0.013 \mathrm{ppm}$ (morning) and $0.012 \mathrm{ppm}$ (evening). These values were lower than the WHO limit of 0.08 ppm, $\mathrm{p}<0.05$ ).

\subsection{Socio-Demographic Characteristics of Women Cooking with Kerosene Stoves}

The preliminary survey in the community showed that most of the cooking occurred in semi-detached, detached or completely enclosed kitchens. About $40 \%$ of the women were sometimes found cooking with their children in the kitchen. Virtually all the women cooking were used to sitting close to the cooking sources and heavy cooking was done mostly in the evening hours at the close of the day's activities. Women that participated in the survey were aged between 15 to 70 years. About $24 \%$ were 30 years and below, 50.3\% were between 31 and 50 years while the proportion of respondents with age range of 51 to 70 years was $25.1 \%$.

The level of education of the respondents revealed that $8.4 \%$ of KSU had no formal education. The proportion with primary, secondary and tertiary education was $26.9 \%, 47.9 \%$ and $16.8 \%$ respectively. Majority $58.1 \%$ of the respondents were traders while others were: artisans $20.4 \%$, farmers $1.2 \%$, housewife $1.2 \%$, civil servant $7.8 \%$, students $10.2 \%$ and clergy $1.2 \%$.

\subsection{Anthropometric Characteristics, Reported Respiratory Symptoms and Lung Function Status of Participants}

The mean age of participants that took part in the lung function test was $37.1 \pm 11.4$ years while the min and max ages were 18 and 65 years respectively. The mean weight was $64.4 \pm 11.9 \mathrm{~kg}$ while the mean height was $1.60 \pm 0.1 \mathrm{~m}$. The mean Body Mass Index (BMI) of KSU was $25.6 \pm 4.6 \mathrm{~kg} / \mathrm{m}^{2}$.

The proportion of respondents that reported respiratory symptoms in the last six month preceding the study among kerosene stove users indicated that running nose had the highest proportion of the respiratory symptom of $26.9 \%$. Other respiratory symptoms were: chest pain (8.4\%), difficulty in breathing (4.8\%), wheezing (10.2\%) tightness of chest (2.4\%) and cough (0.6\%).

The respondents who consented to participate in the lung function test were not significantly different from those who did not concerning key socio-demographic characteristics such as occupation $(\mathrm{p}=0.595)$, education ( $p=0.139)$, frequency of kerosene use $(p=0.422)$, proximity to stove while cooking $(p=0.134)$, indoor cooking $(p=0.742)$ though refusals were slightly older ( 36 years vs 32 years) but statistically significant $(p=0.023)$.

The values of the observed lung function $\left(\mathrm{FEV}_{1}\right)$ for $\mathrm{KSU}$ were expectedly found to decrease with age (see Table 2). Also the predicted $\mathrm{FEV}_{1}$ values were higher than the observed $\mathrm{FEV}_{1}$ values. The mean predicted values of $\mathrm{FEV}_{1}$ was $2.7 \pm 0.5$ litres while the mean observed $\mathrm{FEV}_{1}$ in litres was $2.0 \pm 0.4(\mathrm{p}<0.05)$. The percentage predicted $\mathrm{FEV}_{1}$ for the entire study participants was $73.8 \%$. However, there were variations in the $\% \mathrm{FEV}_{1}$ across the different age groups with the age groups $26-36$ yrs and $37-47$ yrs recording the lowest values (Figure 4).

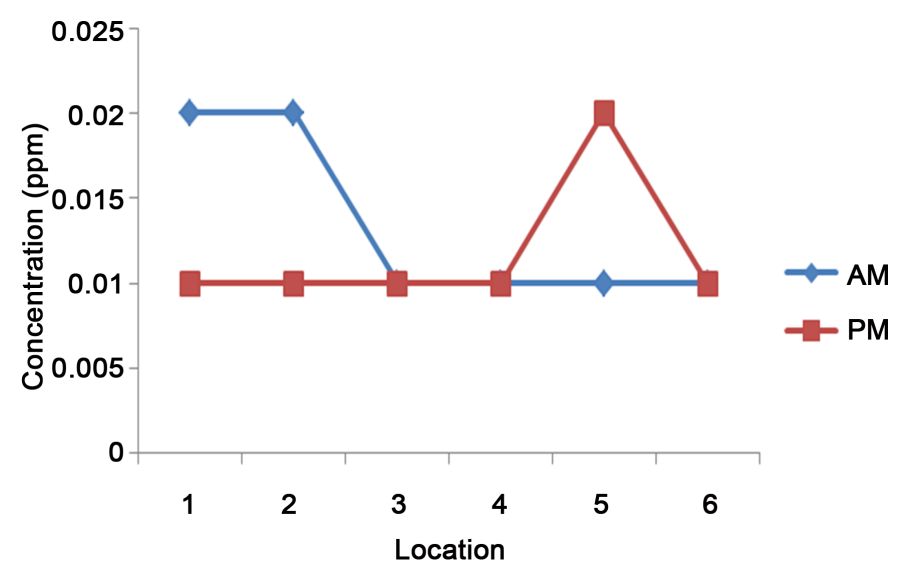

Figure 3. Concentration of $\mathrm{SO}_{2}$ in the morning (AM) and evening (PM) at the different kitchen locations. 


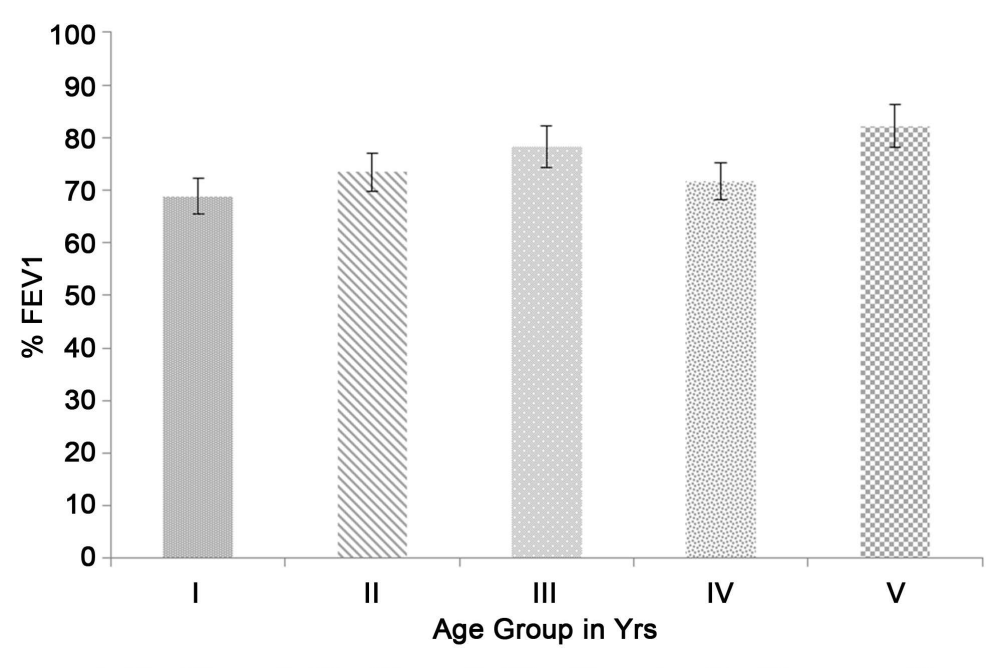

i: 15 - 25 yrs, ii: 26 - 36 yrs, iii: 37 - 47 yrs, iv: 48 - 58 yrs, v: >59 yrs

Figure 4. Variation in $\% \mathrm{FEV}_{1}$ in relation to age.

Table 2. Participant's lung function status in relation to age and body mass index.

\begin{tabular}{|c|c|c|c|c|c|c|c|}
\hline $\mathrm{S} / \mathrm{N}$ & $\begin{array}{l}\text { Age group } \\
\text { (years) }\end{array}$ & $\begin{array}{l}\text { Mean height } \\
\text { (m) }\end{array}$ & $\begin{array}{l}\text { Mean weight } \\
(\mathrm{kg})\end{array}$ & $\begin{array}{c}\text { Mean } \\
\text { BMI }\end{array}$ & $\begin{array}{c}\mathrm{FeV}_{1} \\
\text { observed (l) }\end{array}$ & $\begin{array}{c}\mathrm{FeV}_{1} \\
\text { predicted (l) }\end{array}$ & $\% \mathrm{FEV}_{1}$ \\
\hline 1 & $15-25$ & 1.58 & 60.41 & 24.17 & 1.92 & 2.79 & 68.8 \\
\hline 2 & $26-36$ & 1.60 & 65.66 & 25.73 & 2.10 & 2.86 & 73.4 \\
\hline 3 & $37-47$ & 1.58 & 68.67 & 27.58 & 1.90 & 2.43 & 78.2 \\
\hline 4 & $48-58$ & 1.57 & 65.00 & 26.35 & 1.67 & 2.33 & 71.7 \\
\hline 5 & $\geq 59$ & 1.58 & 59.67 & 23.62 & 1.43 & 1.74 & 82.2 \\
\hline
\end{tabular}

There was a weak positive and insignificant correlation between BMI and $\mathrm{FEV}_{1}$ observed $(\mathrm{r}=0.149, \mathrm{p}=$ 0.212). However, in terms of the relationship between lung function and exposure to $\mathrm{PM}_{10}$ there was no significant correlation between $\mathrm{PM}_{10}$ and $\mathrm{FEV}_{1}(\mathrm{r}=-0.371, \mathrm{p}=0.468)$, see Figure 5 .

\section{Discussion}

Exposure to different forms of biomass emissions from cooking stoves has been implicated by several epidemiological studies to have enormous impacts on the health of populations particularly vulnerable groups such as women and children. This situation has been found to be very acute in developing countries. Unfortunately, very little information is available regarding the level of vulnerability to health risks associated with exposure to kerosene stove emissions in Nigeria. Herein lies the significance of our study.

The mean $\mathrm{PM}_{10}$ concentration for kerosene stove in the morning was $242.81 \mu \mathrm{g} / \mathrm{m}^{3}$ while the evening mean concentration was $253.45 \mu \mathrm{g} / \mathrm{m}^{3}$. The daily mean was $248.1 \pm 14.1 \mu \mathrm{g} / \mathrm{m}^{3}$. The mean concentration of KS emissions was about 10 times higher than the WHO guideline limit of $25 \mu \mathrm{g} / \mathrm{m}^{3}$. Since there is paucity of literature on the level $\mathrm{PM}_{10}$ emitted by kerosene stone we can only compare our result with investigations from biomass fuel. The particulate matter levels recorded in this study is lower than $717 \mu \mathrm{g} / \mathrm{m}^{3}$ for biomass fuel reported by Naeher et al. [10]. Likewise Enkhjargal et al. [11] recorded a mean $\mathrm{PM}_{10}$ concentration of $601.66 \mu \mathrm{g} / \mathrm{m}^{3}$ in a study carried out in Mongolia, Philippines. Balakrishnan et al. [6] in a study of assessment of respirable particulates associated with household fuel use in rural districts of Andhra Pradesh, India reported $\mathrm{PM}_{10}$ concentration from firewood stove as $500.0 \mu \mathrm{g} / \mathrm{m}^{3}$. Typical 24-hours average concentrations in homes using biomass have been reported to have a range of $200-5000 \mu \mathrm{g} / \mathrm{m}^{3}$ [4] [12]-[15].

Airborne particulate matter (PM) has been a subject of major public health concern globally. Its permeation into the airways in humans is known to cause many disorders. Usually the aerodynamic size, number and 


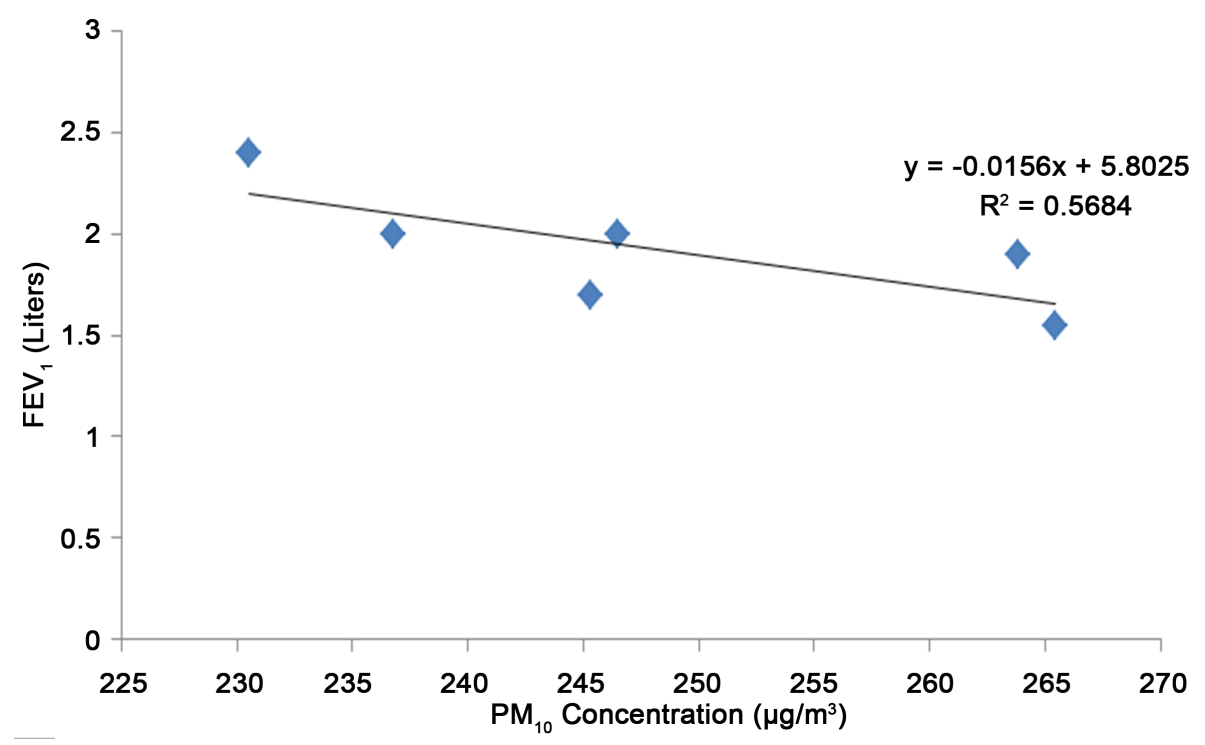

Figure 5. Relationship between $\mathrm{FEV}_{1}$ and exposure to $\mathrm{PM}_{10}$.

concentration of PM in the atmosphere play a vital role in impacting human health. Some epidemiological studies have indicated that exposure to particulate matter can cause cardiovascular and cardiopulmonary damage [16].

Several studies have showed a significant relationship between air pollutant level and $\mathrm{FEV}_{1}$ and FVC. $\mathrm{PM}_{10}$ and $\mathrm{NO}_{2}$ were significantly associated with decreases in $\mathrm{FEV}_{1}$ but only in girls [17]. Gauderman et al. [18] indicated that significant deficit in growth of lung function were associated with exposure to $\mathrm{PM}_{10}$. Avol et al. [19] reported an improvement in lung function in children from Southern California who had moved to areas with lower $\mathrm{PM}_{10}$ and decreased in lung function in subjects who moved to communities with higher $\mathrm{PM}_{10}$. Lagorio et $a l$. in their study on Air Pollution and Lung Function Among susceptible adult subjects observed negative association between ambient $\mathrm{PM}_{2.5}$ and $\mathrm{PM}_{10}$ and respiratory function (FVC and $\mathrm{FEV}_{1}$ ) [20]. The effect on FVC was evident both at a short lag $(24 \mathrm{~h})$ and in relation to cumulative exposures over the previous 24 and 48 hours. The effect on $\mathrm{FEV}_{1}$ appeared only when 72 hours of exposure were accumulated. Horak Jr. et al. in their study on Particulate Matter and Lung Function Growth in Children [21]. A 3-yr follow-up study in Austrian School Children reported that after adjusting for potential confounders (sex, atopy, passive smoking, initial height, height difference, site, initial lung function) an increase of summer $\mathrm{PM}_{10}$ by $10 \mathrm{mg} / \mathrm{m}^{3}$ was associated with a decrease in $\mathrm{FEV}_{1}$ growth of $84 \mathrm{ml} / \mathrm{yr}$ and $329 \mathrm{ml} / \mathrm{s} / \mathrm{yr}$ for $\mathrm{MEF}_{25-75}$. It was concluded by the authors that long-term exposure to particulate matter less than $10 \mathrm{~mm}$ in diameter had a significant negative effect on lung-function proxy for the development of large (forced expiratory volume in one second) and small (mid expiratory flow between $25 \%$ and $75 \%$ of the forced vital capacity) airways, respectively, with strong evidence for a further effect of ozone and nitrogen dioxide on the development of forced vital capacity and forced expiratory volume in one second. Linares et al. carried out a study on Impact of Air Pollution on Pulmonary Function and Respiratory Symptom in children established that $\mathrm{PM}_{10}$ levels had negative relationship with FVC, $\mathrm{FEV}_{1}$ and PEF but with a positive correlation with $\mathrm{FEV}_{1} / \mathrm{FVC}$ according to its change [22].

Most studies that linked lung function with emission from kerosene stove had children as their subjects. Azizi and Henry studied 1600 school children with age range of 7 and 14 years [23]. After adjusting for possible confounders the authors reported mean percent predicted FVC of 95.8\%, PEFR of 97.2\% and FEV 1 of 95.7\%. A decrement of $3 \%-8 \%$ in lung function parameters were reported in children without respiratory symptoms whose family cooked with kerosene [24]. Behera et al. [25] investigated the relationship between fuel type and lung function which led them into recruiting 3991 women from villages in India for the study. Exactly 3318 women actually participated in the study after excluded smokers and those with respiratory symptom from the study. The women were categorised by cooking fuel used: biomass, LPG, kerosene and mixed. The result showed that $\mathrm{FEV}_{1}$ was in the range of $90 \%$ - 94\% of expected. In our study the percent predicted $\mathrm{FEV}_{1}$ was found was $83.33 \%$ which is lower than what was obtained in the study carried out by Behera et al. [25]. The 
study that was carried out in the Niger-Delta region of Nigeria by Mustapha et al. recruited children aged 7 - 14 years. Compared with cooking gas non-significant positive association with phlegm production for cooking with kerosene (OR $=2.83$, 95\% CI: 0.85 - 9.44) was established [26]. It was also reported that the magnitude of associations with night cough, asthma diagnosis (ever), although weaker than for phlegm production, were similar for coal and kerosene.

The First National Health and Nutrition Survey (NHANES) [27] reported that a $34 \mu \mathrm{g} / \mathrm{m}^{3}$ increase in Total Suspended Particulate (TSP) was associated with an average decrease in FVC of 2.2\%. They also found a significant smaller effect for $\mathrm{FEV}_{1}$. In a study conducted in Switzerland, Ackermann-Liebrich et al. 1997 examined 9651 participants in a cross-sectional population based sample of adults (age's 18 - 60 years) and found a significant and consistent effect for $\mathrm{PM}_{10}$. An increase of $10 \mu \mathrm{g} / \mathrm{m}^{3} \mathrm{PM}_{10}$ was associated with $3.4 \%$ reduction in FVC and 1.6\% reduction in $\mathrm{FEV}_{1}$. Regalado et al. 2006 in a study on the effect of biomass burning on respiratory symptoms and lung function in rural Mexican woman reported that current use of a stove burning biomass fuel compared with those cooking with gas was associated with increase reporting of phlegon (27\% vs 9\%) and reduced $\mathrm{FEV}_{1}(79.9 \%$ vs $82.8 \%)$. It was also reported that levels of $\mathrm{FEV}_{1}$ were $81 \mathrm{ml}$ lower and cough was more common in women from homes with higher $\mathrm{PM}_{10}$ concentrations.

Concentrations of $\mathrm{CO}$ and $\mathrm{NO}_{2}$ were below detectable limit. Again the mean concentration of $\mathrm{SO}_{2}$ was 0.013 $\pm 0.005 \mathrm{ppm}$, though lower than WHO limit of 0.14 by a factor of 6 . The possible explanation for this observation could be that there was sufficient aeration to have dispersed the pollutants and or that the efficiency of the stove combustion process was high as at the time of sampling. It would therefore be erroneous to generalize this outcome to other locations which may have had poor stove facilities. A very interesting yet intriguing trend is the low concentrations of $\mathrm{CO}_{2}$ observed in this study. These levels though expectedly higher than other gases measured were below the guideline limits and grossly lower than the global mean of $398.03 \mathrm{ppm}$

(http://co2now.org/).

Spirometry revealed that the age group with the highest $\mathrm{FEV}_{1}$ were those between 26 - 36 years while those with the lowest value were those 59 years and above. Decline in $\mathrm{FEV}_{1}$ was linear. The observed decrease in $\mathrm{FEV}_{1}$ may be more physiological than environmental. The age group with the lowest percentage $\mathrm{FEV}_{1}$ were those between 15 - 25 years followed by those between 48 - 58 years while age group 59 years and above had higher percentage $\mathrm{FEV}_{1}$ which suggested that they were less exposed to emissions from kerosene stoves.

Several studies have associated exposure to cooking stoves with both respiratory and non-respiratory problems [12] [28] [29]. Exposure to smoke had been linked to acute respiratory infections, upper respiratory infection, otitis media, chronic airway diseases, chronic pulmonary disease, pulmonary tuberculosis, asthma, lung cancer, cataract, blindness, low birth weight, meningitis, burns and eye irritation [28] [30]-[37]. The relatively high prevalence of respiratory symptoms among the study population is consistent with that reported by Ibhazehieso et al. who found out that respiratory symptom like cough with sputum production, dyspnirea, wheezing, chest tightness and chest pain were markedly elevated in women that cook with firewood stoves in Edo, Nigeria [38]. However, the lack of comparison group in our study makes attribution of respiratory symptoms to kerosene stove exposure rather difficult.

The limitations of this study are hinged on the fact the design was a snap shot and we did not use personal air monitors in assessing levels of the pollutants. In addition we could not use a $\mathrm{PM}_{2.5}$ particulate sampler which could have been more appropriate for combustion emissions. At the moment it is unclear what local environmental phenomena must have contributed to the low $\mathrm{CO}_{2}$ levels currently observed. It is hoped that future designs with robust methodology and more sensitive equipment will remedy this shortfall. The use of an additional sensitive biomarker such as exhaled nitric oxide for the exposure assessment would have been more revealing. Nevertheless, this pilot study has been able to provide empirical baseline information from which a more rigorous longitudinal design with some elements of causality could be carried out in the future.

\section{Conclusions}

The study was carried out to determine the level of exposures of women in Olorunda community to emissions from kerosene cooking stoves. The pulmonary health status of the exposed women in the community was also assessed.

Our study revealed that the women were exposed to kerosene stoves $\mathrm{PM}_{10}$ emissions that were ten times higher than the WHO guideline limit. However, the levels of gaseous emissions were very low in comparison to 
the guideline limits due to several undefined factors.

Although $\mathrm{FEV}_{1}$ was found to decline with age among the specific age groups particularly with the active class involved in extensive household cooking, it could not be ascertained if the low pulmonary function status was due to exposure to the air pollutants or due to certain confounders.

Therefore, health education should be employed to encourage safe cooking practices and modification of cooking methods by women in the community. Longitudinal studies using biomarkers like upinary polycyclic aromatic hydrocarbons $(\mathrm{PAH})$ metabolites, carboxy haemoglobin $(\mathrm{COHb})$ and exhaled $\mathrm{NO}_{2}$ levels would help in validating exposure assessments in the future.

\section{Acknowledgements}

The authors acknowledge with thanks the support of all field assistants and the community persons throughout the conduct of the study. The technical support received from the Department of Environmental Health Sciences is also gratefully acknowledged.

\section{References}

[1] Semple, S., Devakumar, D., Fullerton, D.G., Thorne, P., Metwali, N., Costello, A., Gordon, S.B., Manandhar, D.S. and Ayres, J.G. (2010) Airborne Endotoxin Concentrations in Homes Burning Biomass Fuel. Environmental Health Perspectives, 118, 988-991. http://dx.doi.org/10.1289/ehp.0901605

[2] The International Energy Agency and Organisation for Economic Cooperation and Development (2004) World Energy Outlook 2004. Paris.

[3] Prüss-Ustün, A., Bonjour, S. and Corvalán, C. (2008) The Impact of Environment on Health by Country: A MetaSynthesis. Environmental Health, 7, 7. http://dx.doi.org/10.1186/1476-069X-7-7

[4] Smith, K.R. (2000) National Burden of Disease in India from Indoor Air Pollution. Proceedings of the National Academy of Sciences of the United States of America, 97, 13286-13293. http://dx.doi.org/10.1073/pnas.97.24.13286

[5] Ahmed, K., Awe, Y., Barnes, D.F., Cropper, L.M. and Kojima, M. (2005) Environmental Health and Traditional Fuel Use in Guatemala. The World Bank.

[6] Balakrishnan, K., Sambandam, S., Ramaswamy, P., Mehta, S. and Smith, K.R. (2004) Exposure Assessment for Respirable Particulates Associated with Household Fuel Use in Rural Districts of Andhra Pradesh, India. Journal of Exposure Analysis and Environmental Epidemiology, 14, S14-S25.

[7] Fajehinsan, A. (1988) A Preliminary Assessment of the Expanded Programme on Immunization (EPI) in Nigeria: The Case of Oyo State, Report of NISER Sponsored Research.

[8] Sridhar, M.K.C. and Ojediran, O. (1983) The Problems and Prospects of Refuse Disposal in Ibadan City, Nigeria. Journal of Environmental Health, 1, 571-575.

[9] Vaughan, N.P., Milligan, B.D. and Ogden, T.L. (1989) Filter Weighing Reproducibility and the Gravimetric Detection Limit. Annals of Occupational Hygiene, 33, 331-337. http://dx.doi.org/10.1093/annhyg/33.3.331

[10] Naeher, L., Leaderer, B., Smith, K., Grajeda, R., Neufeld, L., Mage, D. and Boleij, J. (1996) Indoor, Outdoor and Personal Carbon Monoxide and Particulate Levels in Quetzaltenango, Guatemala: Characterisation of Traditional, Improved and Gas Stoves in Three Test Homes. WHO ARI Programme, Geneva.

[11] Enkhjargal, G., Enkhtuya, P., Suvd, N., Sod-Erdene, N., Baigal, O., Jargalsaikhan, N., Soyolgerel, G. and Randy, V.S. (2004) Health Risk Assessment of Indoor Air Pollution. WHO, Western Pacific Regional Office, Manila.

[12] Ezzati, M. and Kammen, D.M. (2001) Indoor Air Pollution from Biomass Combustion and Acute Respiratory Infections in Kenya: An Exposure Response Study. The Lancet, 358, 619-624. http://dx.doi.org/10.1016/S0140-6736(01)05777-4

[13] Smith, K.R. (1987) Biofuels, Air Pollution, and Health: A Global Review. Plenum Press, New York.

[14] Smith, K. (1989) Dialectics of Improved Stoves. Economic and Political Weekly, 11, 517-522.

[15] Smith, K.R. (1993) Fuel Combustion, Air-Pollution Exposure, and Health-The Situation in Developing-Countries. Annual Review of Energy and the Environment, 18, 529-566. http://dx.doi.org/10.1146/annurev.eg.18.110193.002525

[16] Pope, C.A. and Burnett, R.T. (2002) Lung Cancer, Cardiopulmonary Mortality, and Long-Term Exposure to Fine Particulate Air Pollution. JAMA, 287, 1132-1141. http://dx.doi.org/10.1001/jama.287.9.1132

[17] Peters, J.M., Avol, E., Gauderman, W.J., Linn, W.S., Navidi, W. and London, S.J. (1999) A Study of Twelve Southern California Communities with Differing Levels and Types of Air Pollution. II. Effects on Pulmonary Function. American Journal of Respiratory and Critical Care Medicine, 159, 768-775. http://dx.doi.org/10.1164/ajrccm.159.3.9804144 
[18] Gauderman, W.J., McConnell, R., Gilliland, F., London, S., Thomas, D., Avol, E., et al. (2000) Association between Air Pollution and Lung Function Growth in Southern California Children. American Journal of Respiratory and Critical Care Medicine, 162, 1383-1390. http://dx.doi.org/10.1164/ajrccm.162.4.9909096

[19] Avol, E.L., Gauderman, W.J., Tan, S.M., London, S.J. and Peters, J.M. (2001) Respiratory Effects of Relocating to Areas of Differing Air Pollution Levels. American Journal of Respiratory and Critical Care Medicine, 164, $2067-2072$. http://dx.doi.org/10.1164/ajrccm.164.11.2102005

[20] Lagorio, S., Forastiere, F., Pistelli, R., Iavarone, I., Michelozzi, P., Fano, V., Marconi, A., Giovanni Ziemacki, G. and Ostro, B. (2006) Air Pollution and Lung Function among Susceptible Adult Subjects: A Panel Study. Environmental Health: A Global Access Science Source, 5, 11. http://dx.doi.org/10.1186/1476-069X-5-11

[21] Horak Jr., F., Studnicka, M., Gartner, C., Spengler, J.D., Tauber, E., Urbanek, R., Veiter, A. and Frischer, T. (2002) Particulate Matter and Lung Function Growth in Children: A 3-Year Follow-Up Study in Austrian School Children. European Respiratory Journal, 19, 838-845. http://dx.doi.org/10.1183/09031936.02.00512001

[22] Linares, B., Guizar, J.M., Amador, M., Garcia, A., Miranda, V., Perez, J.R. and Chapela, R. (2010) Impact of Air Pollution on Pulmonary Function and Respiratory Symptom in Children: Longitudinal Repeated Measure Study. BMC Pulmonary Medicine, 10, 62.

[23] Azizi, B.H. and Henry, R.L. (1990) Effects of Indoor Air Pollution on Lung of Primary School Children in Kuala Lumpur. Pediatric Pulmonology, 9, 24-29. http://dx.doi.org/10.1002/ppul.1950090106

[24] Azizi, B.H., Zulfkifli, H.I. and Kasim, S. (1995) Indoor Air Pollution and Asthma in Hospitalized Children in a Tropical Environment. Journal of Asthma, 32, 413-418. http://dx.doi.org/10.3109/02770909409077752

[25] Behera, D., Jindal, S.K. and Malhotra, H.S. (1994) Respiratory Effects of Relocating to Areas of Differing Air Pollution Levels. Respiration, 61, 89-92.

[26] Mustapha, B., Blangiardo, M., Briggs, D. and Hansell, A. (2011) Traffic Air Pollution and Other Risk Factors for Respiratory Illness in School Children in Niger-Delta Region of Nigeria. Environmental Health Perspectives, 119, 14781482. http://dx.doi.org/10.1289/ehp.1003099

[27] Chestnut, L.G., Schwartz, J., Savitz, D.A. and Burchfiel, C.M. (1991) Pulmonary Function and Ambient Particulate Matter: Epidemiological Evidence from NHANES I. Archives of Environmental Health, 46, 135-144. http://dx.doi.org/10.1080/00039896.1991.9937440

[28] Cetinkaya, F., Gulmez, I., Aydin, T., Ozturk, Y., Ozesmi, M. and Demir, R. (2000) Prevalence of Chronic Bronchitis and Associated Risk Factors in a Rural Area of Kayseri, Central Anatolia, Turkey. Monaldi Archives for Chest Disease, 55, 189-193.

[29] Albalak, R., Frisancho, A.R. and Keeler, G.J. (1999) Domestic Biomass Fuel Combustion and Chronic Bronchitis in Two Rural Bolivian Villages. Thorax, 54, 1004-1008. http://dx.doi.org/10.1136/thx.54.11.1004

[30] Robin, L.F., Lees, P.S.J., Winget, M., Steinhoff, M., Moulton, L.H., Santosham, M. and Correa, A. (1996) WoodBurning Stoves and Lower Respiratory Illnesses in Navajo Children. The Pediatric Infectious Disease Journal, 15, 859-865. http://dx.doi.org/10.1097/00006454-199610000-00006

[31] Ellegard, A. (1996) Cooking Fuel Smoke and Respiratory Symptoms among Women in Low-Income Areas of Maputo. Environmental Health Perspectives, 104, 980-985. http://dx.doi.org/10.1289/ehp.96104980

[32] Mishra, V.K., Retherford, R.D. and Smith, K.R. (1999) Biomass Cooking Fuels and Prevalence of Tuberculosis in India. International Journal of Infectious Diseases, 3, 119-129. http://dx.doi.org/10.1016/S1201-9712(99)90032-2

[33] Schei, M.A., Hessen, J.O., McCracken, J., Lopez, V., Bruce, N.G. and Smith, K.R. (2002) Asthma and Indoor Air Pollution among Indigenous Children in Guatemala. Proceedings of Indoor Air 2002, Monterey, 1-7 July 2002.

[34] Smith, K.R. and Liu, Y. (1993) Indoor Air Pollution in Developing Countries. In: Samet, J., Ed., Epidemiology of Lung Cancer, Lung Biology in Health and Disease, Marcel Dekker, New York.

[35] Simmons, G., Martin, D., Stewart, J., Jones, N., Calder, L. and Bremner, D. (2001) Carriage of Neisseria meningitidis among Household Contacts of Patients with Meningococcal Disease in New Zealand. European Journal of Clinical Microbiology and Infections Diseases, 20, 237-242. http://dx.doi.org/10.1007/s100960100478

[36] Gupta, M., Bansal, M., Gupta, A. and Goil, P. (1996) The Kerosene Tragedy of 1994, an Unusual Epidemic of Burns: Epidemiological Aspects and Management of Patients. Burns, 22, 3-9.

[37] Ellegard, A. (1997) Tears While Cooking: An Indicator of Indoor Air Pollution and Related Health Effects in Developing Countries. Environmental Research, 75, 12-22. http://dx.doi.org/10.1006/enrs.1997.3771

[38] Ibhazehiebo, K., Dimkpa, U., Uche, O.K. and Iyawe, V.I. (2007) Peak Expiratory Flow Rate and Respiratory Symptoms Following Chronic Wood Smoke Exposure in Women in Edo State. African Journal of Biomedical Research, 10, 33-39. 